\title{
NUNOBIKI - CAMILO PESSANHA, WENCESLAU DE MORAIS E O "FONÓGRAFO"
}

\section{Paulo de Tarso Cabrini Júnior ${ }^{1}$}

Resumo: Camilo Pessanha, Wenceslau de Morais e o "Fonógrafo". Este artigo procura demonstrar as relações entre a crônica publicada por Wenceslau de Morais (1854-1929), intitulada "A Primavera", e o poema "Fonógrafo", de Camilo Pessanha (1867-1926), que faz parte do único livro lançado pelo poeta português (Clepsydra, de 1920). A comparação propõe novas leituras do poema, e procura contribuir, também, para os estudos acerca do influxo budista na obra de Pessanha.

Palavras-chave: Camilo Pessanha (1867-1926); Wenceslau de Morais (1854-1929); Budismo. Clepsydra; 1920.

Abstract: Camilo Pessanha, Wenceslau de Morais and the "Phonographo"

This article means to clarify the relationship between "A Primavera", a text written by Wenceslau de Morais (1854-1929), and the poem "Fonógrafo", written by Camilo Pessanha (1867-1926), presenting, also, new readings for the poem, and contributing to the studies about the Buddhist strains of Pessanha s work.

Keywords: Camilo Pessanha (1867-1926); Wenceslau de Morais (1854-1929); Buddhism; Clepsydra; 1920.

Toda essa extensa pista - para quê?

Se há-de vir apagar-vos a maré,

Como as do novo rasto que começa...

As pegadas na areia. Camilo Pessanha (1867-1926) tinha uma notória obsessão por "marcas", por "registros", com que pudesse ter a ilusão de deter a passagem do tempo, dos instantes. Como não recordar, agora, dos versos: "Imagens que passais pela retina / Dos meus olhos, por que não vos fixais?" A ânsia de fixar

1. Doutorando em Letras, Universidade Estadual Paulista, campus Assis. 
o tempo, com o objetivo de olhar, mais demoradamente, as coisas queridas, não acreditamos que se deva meramente a uma maneira impressionista de se expressar. O Impressionismo pictórico vigorava, é claro, em sua época, mas, acreditamos que Pessanha, poeta autêntico, visceralmente ligado ao que demandava em seus versos, compartilhava de uma mesma melancolia impressionista, não sendo, portanto, um pastiche. Havia como acreditamos, um "sentimento de época" impressionista; e procuraremos elucidar esse "sentimento", brevemente.

A fugacidade da vida, um dos temas mais caros à filosofia - se não o tema filosófico em si -, nunca havia ficado tão evidente, quanto na época da pintura impressionista. O que a arte pictórica tinha feito, até então, no sentido de "eternizar" os instantes, fornecendo a ilusão de "permanência", o Impressionismo pôs-se a derruir, reproduzindo, até mesmo, o "olhar repentino" do pintor - que é, também, o "olhar repentino" do espectador... A fixação e a demora se viram substituídas pelo soslaio e pela pressa. E os eventos efêmeros tomaram o lugar dos eventos eternos. Conjugada ao tema "proustiano" da "decadência aristocrática", essa efemeridade da vida vulgar, reproduzida em arte, adquiriu matizes de uma melancolia profunda, que não parecia existir, por exemplo, no retrato de um monarca, mas que existe, em profusão, no retrato de uma pobre lavadeira; isso porque os doces momentos de uma vida vulgar passam irremediavelmente, o que a fotografia e a pintura "realistas" tornaram mais acentuado, ao passo que a "eternidade" de um monarca, em pé, em seu gabinete, permanece "fria", como a sua personalidade...

Pintar o "real" nunca havia nos oferecido tanta gama de emoções relativas à passagem do tempo. Mesmo uma pintura de Brueghel (c. 1550), com as suas feiras e festas, ainda nos oferece uma espécie de metáfora, pela qual adivinhamos um sentido "maior", comunicando algo a respeito da vida humana permanente (ou, cíclica). E um pintor como Vermeer (c. 1650) não cremos ter atingido, com os seus retratos do cotidiano, o mesmo grau de dor pela passagem do tempo que as pinturas de Monet ou de Renoir nos despertam.

Efeitos de uma técnica pictórica que envolve em "fumaças" as figuras de jovens e crianças? Talvez. Efeitos de um prosaísmo, muito acentuado, das figuras representadas? Pode ser. Efeitos de uma "prosificação" da "vida cotidiana", mais acentuada no final do século XIX, do que em meados do século XVII? É bem provável. Pois, as figuras impressionistas estão já quase ausentes do que era aristocrático, e quase já despidas dos fatos e adereços, que, hoje, chamamos "enfeites" São figuras tanto mais banais quanto mais tristes, e isso por efeito de um elemento fundamental: o amor. Um amor romântico, ainda, que habita a profundidade dos jardins de Monet, como uma presença, e que habita os olhos pintados por Renoir como um "brilho macio" Há amor, nas representações impressionistas; e esse "romantismo da vida real" torna as suas figuras três vezes mais doloridas de se verem passar... 
A fantasmagoria aristocrática dos prelúdios e das canções de Débussy; a poesia "simbolista" de Mallarmé (que as aspas distinguem do escreveu de mais "moderno", como, por exemplo, o "Lance de dados") parecem comunicar a mesma espiritualização da vida que o sfumato da técnica impressionista nos sugere - malgrado a inexatidão desse termo técnico. Dizia Mallarmé, em "Crise do verso": que era maravilhoso ver um objeto "desfazer-se em vibrações", desaparecer em ondas; ou, em outras palavras, espiritualizar-se (MALLARMÉ, 1945, p. 368). E quantas dessas figuras esvoaçantes, espiritualizadas, despidas de um envoltório carnal, não habitam a poesia de Camilo Pessanha, que clamava: "Oh vem, de branco, do imo da folhagem! (...)"

Quem era essa presença, afinal?... Que parentesco não tem com as "almas", de sombrinha à mão, que passeiam pelos vastos campos, nas pinturas de Monet?...

Mas, a fugacidade do tempo, a efemeridade da vida, a permanência "vibratória" dos objetos reais que partiram, todos são apenas introdução ao nosso assunto principal; e, as obsessões de Camilo Pessanha pela fixação dos instantes, somente o prelúdio do que diremos a respeito de seu poema "Fonógrafo", publicado, pela primeira vez, em 1899, mas, segundo seu autor, escrito em 1896 (PESSANHA, 1994, p. 194).

Vae declamando um comico defunto, Uma platêa ri, perdidamente,

Do bom jarreta... E ha um odôr no ambiente

A crypta e a pó, - do anachronico assumpto.

Muda o registo, eis uma barcarola:

Lirios, lirios, aguas do rio, a lua...

Antes o Seu corpo o sonho meu fluctua

Sobre um paúl, - extática corolla.

Muda outra vez: gorgeios, estribilhos,

D'um clarim de oiro - o cheiro dos junquilhos,

Vivido e agro! - tocando a alvorada...

Cessou. E, amorosa, a alma das cornetas

Quebrou-se agora orvalhada e velada.

Primavera. Manhã. Que effluvio de violetas!

Para estampar o poema, escolhemos a grafia preferida do autor, assim como se estampa na primeira edição de Clepsydra (1920). Sabemos que Camilo Pessanha preferia, por questões estéticas, a escrita "etimológica" à meramente "fonética", já que 
(...) as palavras escritas na sua forma mais arcaica possuem [o poder de] acordar no espírito, dispostas em sucessivos planos, e como que fazendo fundo à idéia que cada uma delas traduz, as imagens das coisas desaparecidas a que essa significação andou associada" ("Literatura chinesa", conferência proferida em 1915, In: PESSANHA, 1993, p. 60).

Indubitavelmente, a grafia antiga, tal como foi preservada, apesar das reformas ortográficas de 1911, acentua a atmosfera "empoada" e "velha" dos versos, na primeira estrofe, assim como acentua a estranheza e o aspecto onírico das "paisagens", nas estrofes seguintes.

Muitas foram as interpretações que se deram ao poema. Para Nuno Júdice, por exemplo, em introdução à edição fac-similada da revista Centauro (1916), Pessanha

vem contestar uma ordem do mundo antiga para propor uma nova visão. Essa ordem contestada é a do Romantismo na sua fase de degradação cujos elementos surgem na primeira quadra: perdida a sinceridade, a adequação referencial, o Romantismo torna-se teatral, no sentido de mover os seus personagens num palco em que são visíveis os cordéis (o deus ex-machina) exteriores à ação (...) Pessanha vem, portanto, anunciar o fim do Romantismo pela denúncia da convenção público-autor. A platéia já não acredita nem pode aceitar a falsa representação que lhe é fornecida e, por isso, ri-se do "cômico defunto", o que amplifica o efeito ridículo da situação. (JUDICE, 1982, p. 11 e 12).

Essa interpretação é bastante perspicaz, colocando o poema como peça crítica de um Romantismo estertorante, nos finais do século XIX; um Romantismo "cadavérico" daria lugar, então, a uma renovação, representada, na segunda estrofe do poema, pela ascensão da lua; e essa renovação, é claro, estaria ligada, ou ao Simbolismo, ou a qualquer forma nova de arte, da qual Pessanha seria um dos anunciadores...

As interpretações, por mais coerentes, sempre têm de se confrontar com dados documentais, o que não as invalida, de forma alguma, devido à natureza própria das obras poéticas. Em nosso caso, o dado documental vem a partir de uma resenha, publicada em 1970, por Pedro da Silveira, que criticava, então, o lançamento da quarta edição do livro de Pessanha, preparada por João de Castro Osório (1899-1970). Nessa resenha, a crônica "A Primavera", de Wenceslau de Morais (1854-1929), é apontada como a fonte do poema de Pessanha; e resolvemos investigar essa curiosa filiação...

Wenceslau de Morais (ou, Venceslau de Morais), oficial da Marinha portuguesa, foi colega de Camilo Pessanha, durante uma rápida passagem, como professor do Liceu de Macau (China). Em 1888, partiria, definitivamente, para o Japão, a exercer funções diplomáticas, vindo a falecer, em idade avançada, na 
cidade de Tokushima. Destacou-se como escritor que noticiava, em livros, e em jornais portugueses, a vida de um europeu "orientalizado" Entre os seus livros, Paisagens da China e do Japão, de 1906, destaca-se por ter sido dedicado a dois de seus amigos e antigos colegas de Liceu: Camilo Pessanha e João Vasco. E, dentre as crônicas e contos publicados no volume, o texto "A Primavera" se dedicava, exclusivamente, a Pessanha... Datado de 1899, esse texto pode ter sido publicado, anteriormente, no Commercio do Porto, periódico que, com freqüência, recebia os textos de Morais, ou em correspondência pessoal a Camilo Pessanha, o que nos ajudaria a compreender como uma crônica de 1899 poderia dar origem a um poema escrito em 1896... Toda a correspondência entre Morais e Pessanha se perdeu, lamentavelmente, e sabemos que essa correspondência era muito volumosa... Não vemos motivo, portanto, para levantar celeuma a partir das datas.

Vejamos, então, a crônica: ela começa com uma exuberante descrição da primavera japonesa, "irrompida", "surgida d'um pulo", "explodida" (MORAIS, 1906, p. 30). O Japão, e, por extensão, o Oriente, é descrito como um lugar onde todas as "grandes forças naturais" são "uns selvagens sem freio" e "sem noção das conveniências", e onde o europeu, "o pobre europeu das paisagens serenas sofre os choques (...) em seu espírito triste, meditativo e atribulado" (MORAIS, 1906, p. 31-2). O que nos importa destacar, porém, são os "charcos", que reaparecerão no poema de Pessanha:

Pela noite velha, fora chegando uma brisa como que amorosa, acariciadora, perfumada. No silêncio das trevas, as carpas acordaram, num charco fronteiro ao meu albergue; e estrebuchavam, e produziam desusados ruídos, saltando fora d'água, ardendo em cios, endemoninhadas (MORAIS, 1906, p. 32).

Já ao longo dos muros espreitam, por entre as pedras, as violetas silvestres; e o solo vai vicejar de musgos, fetos, de relvas, de bambus e de humildes gramíneas; e matizar-se de brancos, de azuis, de amarelos, de escarlates, de roxos, de mil cores, de mil flores sem nome, apenas conhecidas dos insetos, que são botânicos eméritos e sabem de cor e salteado onde as corolas lhes oferecem os manjares mais capitosos. Já desabrocham os junquilhos, as camélias. Vão desabrochar a wistaria, as azáleas, os lírios, os íris, os narcisos, os convólvulos, as peônias, a legião vegetal (MORAIS, 1906, p. 35).

Pelos córregos, pelas regueiras, ao longo das ruas e caminhos, surdiam pela primeira vez das tocas os sapos, rouquejando (MORAIS, 1906, p. 39).

Atualizamos a ortografia, por entendermos que, ao contrário do poema de Pessanha, ela não serve a fins estéticos, mas unicamente às normas ortográficas ainda vigentes. O itálico das citações é nosso, e procura pôr em relevo aquilo que deve ter chamado a atenção de Pessanha, para a construção das imagens do poema... 
A primeira parte do texto descreve, portanto, a "irrupção" da primavera, com as suas flores e os seus personagens típicos; já uma segunda parte nos leva a ambiente, aparentemente, sem nenhuma relação com o primeiro:

(...) me engravatei cuidadosamente e fui bater à porta d'um amigo. Tratava-se duma festa de crianças, o que é dizer, duma estopada para adultos. Efetivamente, exibia-se, em frente duma dúzia de meninos, e de outra dúzia de pessoas circunspectas, um grafofone americano; grafofone, ou coisa parecida; um fone qualquer em todo caso (...). Introduzia-se numa caixa um cilindro apropriado para o caso e dava-se corda ao instrumento... mas a quem estou ensinando o padre-nosso!... Então, um americano fanhoso, embirrante, assim com ares de bêbedo e ademanes de exibidor de saltimbancos, a ponto de se lhe presumir a casaca no fio e cheia de nodoas e a gravata branca em uso há mais de seis semanas, falava ao publico, anunciava a casa construtora em Nova York, e o que em seguida iria ouvir-se (MORAIS, 1906, p. 40-1).

Nesse momento, surge a figura do "fonógrafo", assim como o "bom jarreta", o "cômico defunto", do poema de Pessanha...

E uma plateia ri, perdidamente:

(...) Eram cançonetas chulas, solos de flauta, estrondos de orquestra, devaneios em viola, discursos grotescos; e tudo aquilo, e as vozes do público que ria, que vociferava, que dava palmas, que pedia bis, crianças berrando, damas mal sufocando o riso, cavalheiros atirando chufas, tudo aquilo, distintamente, saía da caixa enfeitiçada e enchia a sala onde me achava, como se uma multidão de patuscos, vindos da América, vindos do inferno, a tivesse invadido de surpresa. (MORAIS, 1906, p. 41)

\section{Há um odor a cripta e a pó, do anacrônico assunto:}

Agora é o grafofone, que eterniza os sons, a voz dos de longe, a voz dos que morreram. Morte, ausência, já não tem razão de existir nos dicionários. Para o caso a que me refiro, cá continua o americano embirrante a vomitar os seus discursos, os músicos a tocarem, os cantores a cantarem, o publico a rir, a chorar, a aplaudir, a chalaçar. Passaram-se assim as cenas há dois anos, há cinco anos, há dez anos. Estará a estas horas o americano morto, coisa de alguma bebedeira mais forte, que o prostrou? A criança, que chorava, dormirá também num tumulo, coitadita? A dama, que ria, estará doida, num asilo? O homem, que aplaudia, num cárcere, cumprindo uma sentença? Nada importa. A máquina chama-os, reúne-os, ressuscita-os, renova-os para a pândega dum momento da existência; o passado é presente; e a máquina agita-os, empurra-os para o interior das nossas casas, para nos divertirmos á custa deles mesmos... (MORAIS, 1906, p. 42-3)

A crônica de Wenceslau de Morais termina por unir os dois assuntos em uma terceira e última parte, onde supõe a maneira pela qual a modernidade pre- 
servaria os sons da cachoeira de Nunobiki, um lugar irremediavelmente avariado pela construção da barragem de mesmo nome:

Cilindro apropriado; dá-se corda... A plebe ouve pouco mais ou menos o seguinte: "Grande companhia de grafofones de Nova York e de Paris! Cena da famosa cascata de Nunobiki, no Japão!". E a plebe continua a ouvir: agora é o murmúrio contínuo, soluçante, de água despenhando-se de rocha em rocha; trina um pássaro vagabundo (...) (MORAIS, 1906, p. 49)

Preservada numa gravação "grafofônica": seria esse o destino do conjunto de cachoeiras denominado Nunobiki, consagrado por séculos de pintura e de poesia. Normalmente, Wenceslau de Morais deploraria essa "afronta" à "tradição" com argumentos bastante duros, já que era, em linhas gerais, um conservador; mas, no caso de Nunobiki, limita-se a dizer que o desaparecimento daquele "poço" era uma lástima, "se é que vale a pena nos prendermos a ninharias" (MORAIS, 1906, p. 46). Desfaz-se o perigo, sempre presente, de considerarmos o autor um "reacionário" - o que é fácil, se nos mantemos presos a uma boa extração de suas obras...

A crônica apresenta, portanto, o seguinte percurso: da Vida à Morte, e da Morte a uma Sobrevida, que não é das mais desejáveis, mas que o autor encara com bastante humor... Expliquemo-nos: da "primavera", que irrompe com as suas cores e personagens doces e meigos, a uma "festa" de crianças, em que a lástima da existência humana é exposta por meio do aparelho denominado "grafofone" ("gramofone", na verdade). E, dessa "festa" de "mortos", vamos à sobrevida que a modernidade oferece até mesmo às coisas consagradas, como as cachoeiras de Nunobiki. O poema de Pessanha, porém, apresenta um outro percurso, partindo da Morte, representada pela reunião social, e pelo "fonógrafo", e gradativamente nos conduz à Vida, representada pela irrupção da "primavera" Da Vida à Morte, no primeiro caso. Da Morte à Vida, no segundo.

Aqui, aparentemente, terminam as considerações a fazer entre a crônica e o poema. A Pessanha, poeta obcecado pela fixação dos instantes, deve ter chamado muito a atenção o aparelho que torturou Morais... O que nos importa, porém, é fazer um desvio em direção à última estrofe do "Fonógrafo", de Pessanha:

Cessou. E, amorosa, a alma das cornetas

Quebrou-se agora orvalhada e velada.

Primavera. Manhã. Que effluvio de violetas

Consideremos essa estrofe, com o seu destacado em negrito, e vejamos se não tem relação com esta frase de Buda, tal como foi traduzida por Guilherme de Almeida: "Alcançarás o Nirvana quando te tornares insensível como um clarim quebrado: não mais terás altercações" (ALMEIDA, 1967, p. 114). 
No poema de Pessanha, há uma deliciosa ambigüidade, criada pelo fato de que muitas flores se parecem, mesmo, a "cornetas" $e$ "clarins"... O que nos chama a atenção, porém, e obviamente, é o fato de que "a alma das cornetas" se "quebrou", no "Fonógrafo", assim como o "clarim" se "quebra", na frase de Buda, e ambos produzem um "estado de Graça" que o primeiro autor não denomina, mas que o segundo chama de Nirvana.

As relações entre Pessanha e a doutrina budista já foram extensivamente apontadas por muitos autores, mas nunca foram exaustivamente, nem sequer detidamente estudadas. Não é o caso de fazermos isso agora; nosso objetivo é, simplesmente, contribuir para um estudo futuro - nosso, ou alheio. "Fonógrafo", é claro, está incluído nessa hipotética investigação, por constituir-se numa espécie de representação da "fuga" de um mundo convencional, da "quebra de decoro" que nos leva a uma "verdadeira vida" $\mathrm{O}$ "fonógrafo" torna-se, desse modo, um "símbolo" do indivíduo que reproduz, em sua mente, os sons da sociedade, as suas ideias, os seus preconceitos, etc., ao passo que, atingindo o Nirvana, esse mesmo indivíduo deixa de responder às pressões, aos "sopros" da sociedade, como um clarim que, apesar de poder ser manuseado e soprado, não emite som algum, por estar quebrado, inutilizado para esse fim...

A lenda nos diz que Buda alcançou a sua "Iluminação" espiritual na manhã do oitavo dia de suas meditações... Foi naquela "manhã" que deixou, definitivamente, o mundo dos "mortos", e conheceu a Vida. Já não era mais facilmente tocado pelo que o rodeava, como a maior parte dos homens o é, nem reproduzia mais as emoções com a assombrosa facilidade com que o fazemos. Tornou-se capaz de não reagir às sugestões do mundo, atingindo tal estado de "firmeza mental", que se viu transformado, segundo a expressão de Borges, em uma "ilha em meio à tempestade" (BORGES, 1983).

Tal era o objetivo de Camilo Pessanha, perseguido repetidamente, em poemas como "Inscrição", por exemplo. Há, é claro, muita semelhança entre o "desejo de aniquilamento", de "silêncio", de "não-vida", em Pessanha, e o Nirvana búdico. Mas, como já foi apontado por diversos autores, inclusive por Ester de Lemos, autora de um dos estudos fundamentais a respeito da obra do poeta português, esse desejo de "impassibilidade" não se concretiza "budicamente", em Pessanha, por faltar, ao poeta, o objetivo "religioso" imprescindível à obtenção de tal estado; em outras palavras, a busca de "tranqüilidade", em Pessanha, baseava-se num desespero, mais do que numa fé religiosa, o que torna o seu "desejo de aniquilamento" mais um "suicídio" do que um "estado nirvânico" propriamente dito. Há, indiscutivelmente, "budismo", em Pessanha. Mas, um "budismo" que encontra um homem do século XIX europeu, às voltas com uma educação positivista, colonialista, cientificista, e materialista; um homem, ao mesmo tempo, excessivamente apegado às imagens do seu passado, e de sua infância; excessivamente amoroso para ser o "funcionário ideal" do Estado, despido de sentimentalidade, 
frio e analítico; mas, também, excessivamente impregnado desses "ideais", para ser um autêntico "religioso"

Concluímos essa passagem rogando por mais estudos que contemplem a faceta budista de Camilo Pessanha. Acreditamos que isso nos daria a oportunidade de percebermos uma passagem fundamental da vida no Ocidente, quando, inadvertidamente, penetramos no Oriente com o espírito missionário, obtendo, ao invés de obediência, lições preciosas a respeito de nós mesmos, assim como Roma se impregnou da Grécia, ao invés de submetê-la. Um último dado, porém, falta ao nosso estudo. Trata-se de uma chave de interpretação, que nos é dada pela crônica de Morais. Vejamos que, na terceira parte de seu texto, ao comentar a respeito da cachoeira de Nunobiki, o autor menciona a casa de chás, que funcionava contiguamente à cachoeira principal (que ele denomina, simplesmente, "o poço"). Duas atendentes trabalhavam nessa casa de chás, e uma delas se chamava "Senhora Primavera" Primavera havia falecido... E, ao autor, não escapa a ambigüidade criada pela "Primavera" que "irrompe", na primeira parte de seu texto, e a "Primavera" que morre, no final da crônica... O interessante, porém, é que, na passagem em que Morais descreve a gravação, para a posteridade, da cachoeira de Nunobiki, a moça apareça, nestes termos:

(...) a plebe continua a ouvir: é agora o murmúrio contínuo, soluçante, de água despenhando-se de rocha em rocha; trina um pássaro vagabundo; um francês bate as palmas, pede cerveja; um inglês pede whisky; um nipônico pede chá; a voz da Senhora Primavera vibra distinta, fresca, doce; Primavera desfaz-se em desculpas, em risinhos, diz que já vai, não tarda; mas o inglês tem pressa, renova o seu pedido com azedume; e o instrumento é então perfeito - oh, maravilha da ciência! - que se ouve até o ciciar dum beijo, que é naturalmente do francês... (MORAIS, 1906, p. 49)

Isso nos dá uma chave de interpretação, que é a seguinte: partida, já, de um mundo feito "anacrônico", e de uma plateia que ri, já, "perdidamente"; partida de entre aqueles que, para si, já são apenas "cômicos defuntos", a Senhora Primavera se encontra em êxtase, sobre o paúl de lembranças, de reminiscências da sua vida recém-deixada; flutua diante da Lua, e ouve-se, então, uma barcarola (que diferença do que se ouvia na casa de chás!...). Em seguida, vêm os sons estridentes de uma antemanhã, e as sensações vívidas, que conduzem ao florescer silencioso de todas as violetas, que já espreitavam, pelos muros, e que colorem, agora, o caminho à Verdadeira Vida. Senhora Primavera irrompeu... Rompeu-se. Nasceu, verdadeiramente...

\section{Referências Bibliográficas}

ALMEIDA, Guilherme de. As Palavras do Buda. Rio de Janeiro: Ediouro, 1967.

BORGES, Jorge Luís. O Budismo. In: Sete Noites. São Paulo: Max Limonad Ltda., 1983. 
JÚDICE, Nuno. Da Afirmação Simbolista à Decadência. In: Centauro, edição fac-similada. Lisboa: Contexto, 1982.

LEMOS, Ester de. A Clepsidra de Camilo Pessanha. $2^{\text {a }}$ ed. Lisboa: Verbo, 1981.

MORAES, Wenceslau de. Paisagens da China e do Japão. Lisboa: Tavares Cardoso, 1906.

SILVEIRA, Pedro da. Clepsidra e Outros Poemas - resenha. Colóquio, n. 60. Outubro, 1970, p. 78.

MALLARMÉ, Stéphane. Ouvres Complètes. Paris: H. Mondor and G. Jean-Aubry, 1945.

PESSANHA, Camilo. China: Estudos e Traduções. Lisboa: Veja, 1993.

. Clepsydra. Lisboa: Lusitania, 1920.

. Clepsydra. Campinas (SP): Unicamp, 1994.

Nunobiki, cachoeira principal, 189 ?

Localização no texto: final do artigo

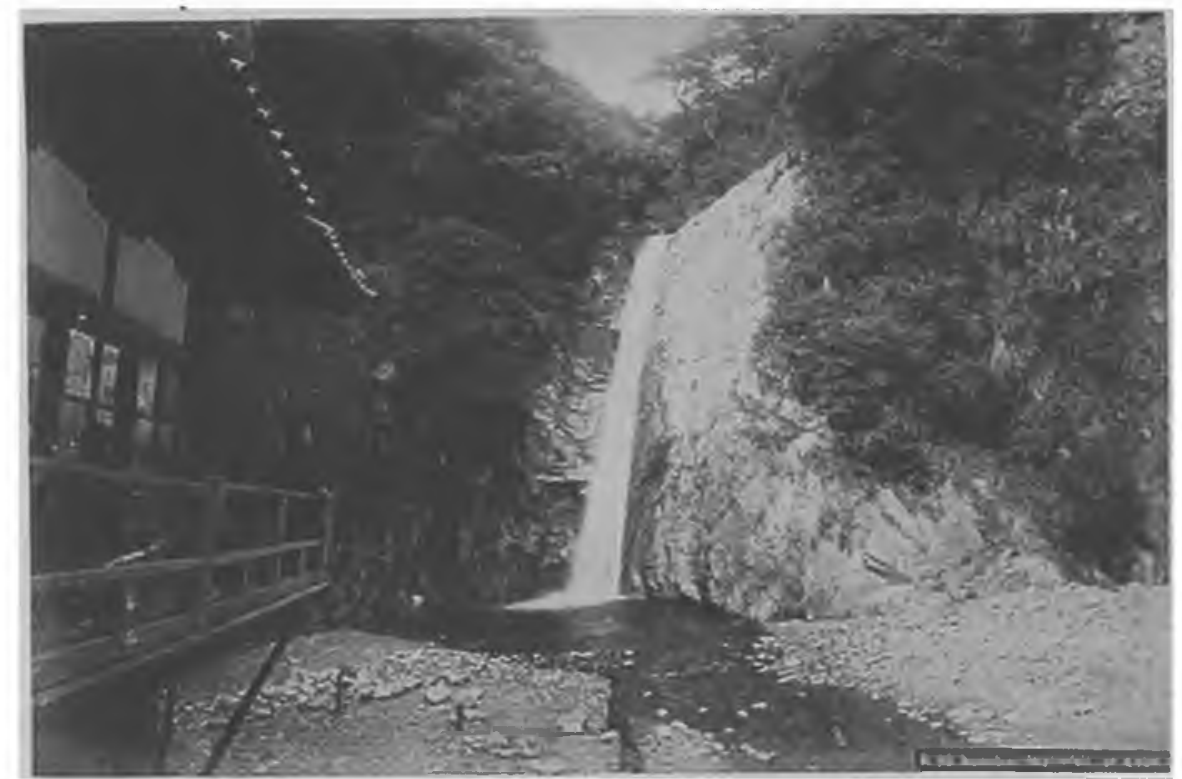

Disponível em http:/www.flickr.com/photos/nypl/3110743182/ 